\title{
O GÊNERO TEXTUAL FAKE NEWS
}

\section{FAKE NEWS AS A TEXT GENRE}

\author{
Marina Chiara Legroski* \\ $U E P G$
}

Resumo: O presente trabalho pretende, em linhas gerais, abordar questões referentes a um gênero textual em circulação na contemporaneidade, as fake news, contemplando aspectos concernentes à Linguística Textual, como fatores de textualidade (KOCH, 2009) e suporte (MARCUSCHI, 2008). Com base nesta discussão, pretendemos elencar pontos sensíveis em relação a essas práticas, bem como proporcionar uma análise de fatores sociais que são colocados em cena com este tipo de texto, na tentativa de sensibilizar a comunidade que recebe estes textos para sua correta identificação.

Palavras-Chave: Fake news. Linguística textual. Gênero textual.

\begin{abstract}
This paper intends, generally speaking, to address issues related to a textual genre that circulates in contemporary times, known as 'fake news', by contemplating aspects concerning Textual Linguistics, such as textuality factors (KOCH, 2009) and support (MARCUSCHI, 2008). Based on this discussion, we intend to list sensitive points related to these practices, as well as providing an analysis of social factors that are presented with this genre, in an attempt to sensitize the community that receives these texts for their correct identification.
\end{abstract}

Keywords: Fake news. Textual linguistics. Textual genre.

\section{INTRODUÇÃO}

Sendo um assunto bastante em voga na atualidade, falar sobre Fake News é se embrenhar em um caminho cheio de possibilidades e desdobramentos complicados, tanto no aspecto social quanto nos aspectos éticos, pois muitas seriam as formas possíveis para abordar esse assunto. A escolha que faço neste trabalho pela abordagem da Linguística Textual não é gratuita: acredito que esta é uma disciplina consolidada com categorias analíticas importantes para abordar o fenômeno em si, mas que também prezam pelo olhar com o texto em relação à sua repercussão e inserção na sociedade.

Neste sentido, este trabalho não pretende colocar fake news dentro de uma tipificação de gêneros textuais, mas como mote de uma discussão a respeito de como estas vêm a ser entendidas por seus receptores como verdadeiras a partir de elementos textuais e sociais, bem como de que forma a caracterização e o entendimento desses elementos poderiam nos ajudar a erradicar esse tipo de conteúdo das práticas sociais. Sabemos que não é a primeira vez na história em que notícias enganosas circulam, bem como também não é a primeira vez que a população se sente tentada a acreditar em fatos cuja veracidade e fidedignidade são postas à prova por seus pares

\footnotetext{
* Doutora em Letras pela Universidade Federal do Paraná (UFPR). Professora adjunta do Departamento de Estudos da Linguagem (DEEL) da Universidade Estadual de Ponta Grossa (UEPG). E-mail: marinalegroski@gmail.com.
} 
sociais, mas talvez seja a primeira vez na história em que esses feitos sejam usados de forma criminosa e que, pelo acesso disseminado a meios de comunicação, qualquer pessoa pode vir a ser criadora e consumidora deste tipo de conteúdo.

O objetivo deste trabalho é analisar fake news divulgadas por meio da internet, explicitar aspectos formais desse conteúdo que permitem que identifiquemos que se trata de fake news, problematizar e discutir as situações de produção e recepção desses textos e mapear elementos que possibilitem a rápida identificação dessas notícias antes de que elas sejam incorporadas nos discursos e práticas sociais e, portanto, que as pessoas possam agir em relação ao seu conteúdo.

\section{FAKE NEWS E SUA FUNÇÃO COMUNICATIVA}

Qualquer teoria que se pretenda a estudar textos, como colocado anteriormente, vai levar em consideração não apenas seus aspectos formais, mas também as suas condições de produção e recepção. Quem produz o texto, com que intenção, onde veicula, quem será o interlocutor, que conteúdos serão mobilizados são aspectos indissociáveis de sua construção linguística. Nada em um texto é por acaso. As estratégias colocadas em jogo, portanto, são multifacetadas. Segundo uma definição clássica, texto é uma

unidade linguística concreta - perceptível pela visão ou audição - que é tomada pelos usuários da língua - falante, escritor/ouvinte, leitor -, em uma situação de interação comunicativa, como uma unidade de sentido e como preenchendo uma função comunicativa reconhecível e reconhecida, independentemente da sua extensão (KOCH; TRAVAGLIA, 1991, p. 10).

Para o caso em tela neste texto, as fake news, acredito que os aspectos mais centrais serão justamente os exteriores à sua materialidade linguística, ou seja, as situações interacionais e as funções comunicativas envolvidas nestas práticas. É impossível pensar e discutir fake news sem se levar em consideração estes aspectos. As fake news, seriam, portanto, um novo gênero textual na medida em que inovam na interligação de aspectos formais e sociais nunca antes postos em funcionamento desta forma. Consideremos o que Silva (2007) coloca, a partir de Bazerman (2005), sobre práticas sociais e gêneros textuais ou discursivos:

Em seus estudos linguísticos, Bazerman (2005) parte de uma perspectiva sócio-interativa, revelando que os gêneros estão intimamente ligados a fatos sociais e atividades humana. [...] O que é ressaltado o tempo todo por Bazerman é a relação entre gênero e organização de atividades sociais; já que os textos, segundo o autor, são responsáveis pelo estabelecimento e surgimento de fatos sociais, os quais regem e orientam a vida social (SILVA, 2007, p. 22-23).

Tendo em vista que o comportamento social vem sendo diretamente afetado pelas fake news, levando inclusive à eleição de presidentes de nações (como é o caso dos Estados Unidos, em 2016, e do Brasil, em 2018), cabe olhar com certo cuidado para estes textos em circulação.

Evidentemente, elementos de forma são os primeiros que saltam aos olhos quando pensamos em um texto: configuração espacial, tamanho, formato, usos lexicais; enfim, nota-se o aspecto visual e linguístico de um texto. Neste sentido, recentemente, um grupo de alunos e 
professores da Faculdade de Ciências Farmacêuticas de Ribeirão Preto (FCFRP) da USP criaram uma espécie de manual que identifica “a anatomia das fake news”. ${ }^{1} \mathrm{O}$ material é extremamente interessante e tem o objetivo de dialogar com um público mais amplo o possível, de modo que mistura elementos textuais, visuais e dicas de onde buscar informação de qualidade na sua análise. O manual se concentra em fake news divulgadas em grupos de Whatsapp (sobre o que falaremos adiante), e mostra exemplos de análises diagonais, que passam por aspectos linguísticos normativos (algo como “desconfie de erros ortográficos”), bem como aspectos semânticos ("desconfie de afirmações inéditas demais”) e sociais ("participe de grupos de divulgação científica”). Creio que esse é um material extremamente relevante para pensar nos aspectos formais das fake news, mas que não as esgota, uma vez que o suporte onde estas informações são veiculadas são diversos e alguns destes aspectos podem ser diferentes a depender do material que temos diante dos olhos.

\section{UMA TENTATIVA DE DEFINIÇÃO}

A equivalência quase imediata que um falante de português faz de fake news com "notícias falsas” é simplista, porque, como veremos, o problema vai além disso. Fake news não são apenas notícias falsas, pois não se tratam apenas de textos cujo conteúdo veiculado é falso (em que se pese o contraste com a realidade circundante), mas nos quais este conteúdo é intencionalmente produzido para ser falso. Uma "notícia falsa” pode acontecer por imprecisões jornalísticas, pela alteração no que se sabe sobre os fatos (por exemplo, uma investigação de um crime que aponta para um culpado que, posteriormente, se descobre ser inocente), por uma informação errada que tenha sido passada etc. Enfim, em qualquer um destes casos, em busca de credibilidade, o meio de comunicação ou o autor do texto pode vir a público atualizar as informações, desmentir os fatos ou, de qualquer outra forma, reestabelecer a conexão com a realidade circundante.

Fake news, por outro lado, é um texto criado com a finalidade de ser falsa. Biondo (1994), retomando Coleman e Kay (1981), ao definir “mentira”, estabelece que esta se dá por uma conjunção de 3 fatores:
(a) P é falso.
(b) F sabe que P é falso.
(c) F pretende enganar $\mathrm{O}$.

Desta forma, uma mentira prototípica é aquela em que o falante diz algo deliberadamente falso e com a intenção de enganar (BIONDO, 1994, p. 11).

Tomando por base estes parâmetros, uma fake news não é apenas uma "notícia falsa”, e sim uma "notícia” criada deliberadamente com a intenção de enganar o interlocutor, pois seu enunciador/criador sabe que o que está veiculando é falso. Dito de outra forma, o conteúdo veiculado é falso, o produtor do texto que contém esse enunciado sabe que o seu conteúdo é

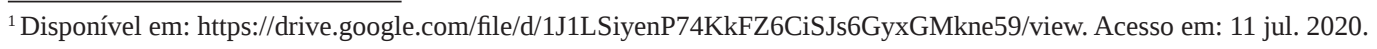


falso e o produz com a finalidade de fazer com que seu interlocutor não o identifique como sendo falso, da mesma forma como ocorre a produção de mentiras.

Contudo, comparar fake news à mentira seria bastante simplista e insuficiente, uma vez que existem diversas camadas que fazem dele um fenômeno mais poderoso e multifacetado. Paródias, por exemplo, também são “notícias falsas” (ou “mentirosas”), também são criadas com o intuito de enganar o leitor, mas seu objetivo é o de causar humor. Sites como The Onion ${ }^{2}$ (em inglês), ou O Sensacionalista ${ }^{3}$ e o Piauí Herald ${ }^{4}$ (em português) são notórios justamente por esse tipo de produção. É fato que muitas pessoas são confundidas por estes textos, mas o caráter satírico é percebido por parte de seus leitores que prontamente podem desfazer o equívoco. Então, fake news ainda não é isso.

A característica mais socialmente danosa que emerge das fake news compartilhadas em mídias sociais é justamente seu caráter de rápida disseminação. Somado ao fato de que a notícia é enganosa e criada para tanto, ela precisa se espalhar o mais rápido possível para o maior número de pessoas, uma vez que não basta apenas enganar: seu objetivo é o de levar à desinformação.

Para o seu rápido compartilhamento, as mídias sociais desempenham um papel fundamental. Através da ativação de mecanismos cognitivos que não passam pelos processos racionais, mas pelos mais instintivos, de tomada de decisão rápida, as fake news precisam ser criadas para gerar a maior incongruência possível dentro de uma base relativamente conhecida. Dito de outra forma, são feitas para "gerar engajamento”.

Há ainda uma distância entre a partilha dos links e a sua leitura em si. Estudo divulgado em junho de 2016 pela Universidade de Columbia e o Instituto Nacional Francês mostra que 59\% dos links partilhados em redes sociais não chegam a ser clicados de facto (Dewey, 2016). Dessa forma, uma manchete atraente - que normalmente fica explícita na URL do link - já seria suficiente para garantir engajamento (DELMAZO; VALENTE, 2018, sem paginação).

Considerando-se, portanto, que o que está sendo disseminado muitas vezes não foi ou será lido, a intenção deixa a de ser apenas a de enganar, mas de buscar formas de enganar o máximo de pessoas o mais rápido possível, com a menor quantidade de texto possível. Porém, como há diversas fontes de informação com diferentes conteúdos veiculados, no contraste entre o conteúdo de uma fake news e o de uma notícia verdadeira, o efeito gerado não tem sido o de confronto entre dois mundos possíveis, mas o de produzir desinformação: quando se desacredita uma fonte, se desacreditam todas as outras.

A credibilidade da informação, ainda, é um ponto a ser salientado: quando pensamos em fake news compartilhadas em redes sociais, muitas vezes, com links e urls que somos incapazes de reconhecer ou muito semelhantes aos de portais conhecidos, não estamos ligando a informação passada ao veículo que a produziu, mas a quem o compartilhou. Isso fica ainda mais evidente quando se pensa em fake news compartilhadas por Whatsapp, por exemplo. A “informação" chega até nós por meio de uma fonte conhecida, fidedigna (até que se prove o contrário) e,

\footnotetext{
${ }^{2}$ Disponível em: https://www.theonion.com/. Acesso em: 28 nov. 2020.

${ }^{3}$ Disponível em: https://www.sensacionalista.com.br/. Acesso em: 28 nov. 2020.

${ }^{4}$ Disponível em: https://piaui.folha.uol.com.br/herald/. Acesso em: 28 nov. 2020.
} 
portanto, com um estofo pragmático e social que nos permite acreditar que se trata de algo relevante. A aceitabilidade do leitor àquele tipo de conteúdo já está minimamente garantida.

\section{FAKE NEWS EM OPOSIÇÃO À NOTÍCIA}

Retomando a tradução literal do termo que fizemos no item anterior, outro ponto que não pode ser desconsiderado é o fato de que "notícias falsas” nos leva diretamente à discussão de o que seria uma notícia. Considerar que fake news são notícias é uma imprecisão terminológica, uma vez que este é um gênero textual relativamente consolidado nas nossas práticas sociais cotidianas, enquanto aquele ainda é um território incerto que tenta, em parte dos casos, emular o gênero. Fake news se disseminam, inclusive, em territórios onde "notícias" não conseguem chegar. Por conta das contingências das redes sociais, os textos que circulam por ali e são, também, chamados de fake news, possuem aspectos formais que nem de longe se assemelham ao de uma notícia.

Silva (2007) se propõe a fazer uma tipologia textual do gênero “notícia”. Para esta autora, os aspectos que diferenciam este de outros gêneros textuais são linguísticos, mas estão aliados a aspectos imagéticos:

textos como a notícia, gênero jornalístico de grande ocorrência, [pode] ser constituída ora apenas por signos linguísticos e ora por estes e imagens (fotos, gráficos, mapas, esquemas etc), que auxiliam no estabelecimento da coerência, funcionando como contextualizadores (SILVA, 2007, p. 15-16).

Por ser um gênero textual dos mais presentes no cotidiano, Silva (2007) defende que qualquer usuário da língua (acrescento: um cidadão letrado) tenha condições de reconhecê-la, inclusive entre outros textos da esfera jornalística.

Essa capacidade de identificação do texto noticioso se deve, principalmente, à sua estrutura convencional, a qual permite que reconheçamos uma notícia, mesmo havendo variações regionais e nacionais. Segundo Van Dijk (1986), há uma superestrutura ("news schemata”) convencional que organiza as notícias do jornal impresso, definida pelo autor como "propriedades estruturais abstratas do discurso, como representações, e como sistemas de regras, normas ou estratégias socialmente compartilhadas para o uso da notícia (VAN DIJK, 1986, p. 155, apud SILVA, 2007, p. 8).

Ou seja, por terem um formato mais ou menos estável, notícias não apresentam grandes modificações em suas estruturas, sejam estas textuais ou imagéticas. É um gênero bastante estável, do qual se esperam mais ou menos as mesmas configurações e a mesma qualidade de informações dispostas mais ou menos na mesma ordem. Sobre isso, a autora complementa:

Existe, portanto, uma superestrutura da notícia, que confere a esse texto uma certa regularidade de forma e conteúdo, uma vez que as categorias esquemáticas são “preenchidas” por proposições semânticas, as quais são responsáveis pelo elo ("link”) entre as categorias da superestrutura, que são abstratas, e a superfície do texto, ou seja, as palavras e sentenças (SILVA, 2007, p. 41). 
Essa estabilidade relativa do gênero serve, para as fake news, como um "atalho interpretativo": ao reconhecer o gênero, o leitor do texto se "desobriga” de verificar as informações ali veiculadas, uma vez que acredita que a verificação já foi feita pelo autor do texto. Ora, a expectativa de um leitor de notícias não é ter que verificar seu conteúdo, mas apenas de tomá-lo como verdadeiro e informativo.

O caráter transmidiático das fake news que mencionamos acima faz com que este também seja um gênero que faz uso de imagens (principalmente emojis, como descrito no manual de identificação citado anteriormente), mas não apenas isso: fake news não são apenas notícias em portais, não são apenas textos compartilhados em redes sociais, não são apenas links que chegam aos nossos e-mails: elas são isso e, ainda, outras coisas. Pode haver fake news que chegam por áudio, fake news que são o uso descontextualizado de imagens ou, ainda, legendas mentirosas para fotos reais, recortes e edições em materiais visuais que destaquem determinado aspecto e apaguem outro etc. Para que a aceitabilidade destes textos esteja assegurada, cabe discutir o "suporte” que os traz para a circulação.

\section{SUPORTE}

A definição clássica de suporte que trazemos aqui retoma os trabalhos de Marcuschi (2008), que, a partir do trabalho com gêneros, pensou que há

um lócus físico ou virtual com formato específico que serve de base ou ambiente de fixação do gênero materializado como um texto. Pode-se dizer que suporte de um gênero é uma superfície física em formato específico que suporta, fixa e mostra um texto (MARCUSCHI, 2008, p. 174).

Além disso, para este autor, a relação entre o gênero e seu suporte é tal que não há como um gênero circular sem suporte e este tem um peso importante sobre aquele. "A ideia central é que o suporte não é neutro e o gênero não fica indiferente a ele” (MARCUSCHI, 2008, p. 174). O autor considera que a internet é um "suporte que alberga e conduz gêneros dos mais diversos formatos. A internet contém todos os gêneros possíveis” (MARCUSCHI, 2008, p. 186).

Fazendo apenas um esforço interpretativo, é possível afirmar, então, que a internet não só abriga, mas também cria novos gêneros, na medida em que o relacionamento deste suporte com as ocorrências linguísticas ali veiculadas vai moldando e afetando o gênero de forma que ele se remodela, tanto em termos de forma quanto de conteúdo. Acredito que é apenas assim que olhamos para um texto como (01) abaixo, que não possui formato de notícia, não está suportado por um jornal ou portal, e o entendemos como "noticioso":

(01) Boas notícias:

Informações para todos, o COVID-19 é imune a organismos com um PH maior que 5,5.

VIROLOGY Center, Moscou, Rússia.

Precisamos consumir mais alimentos alcalinos que nos ajudem a aumentar o nível de $\mathrm{PH}$, para combater o vírus. 
Alguns dos quais são:

\begin{tabular}{|c|}
\hline mão \\
\hline 15,6 $\mathrm{Pl}$ \\
\hline ...... 13,2 P \\
\hline ........ 8,7 P \\
\hline$\checkmark$ Tangerina. \\
\hline$\ldots 12,7$ \\
\hline \\
\hline
\end{tabular}

Não guarde essas informações apenas, para você.

Passe para toda a sua família e amigos.

Tome cuidado e Deus te abençoe.

O texto em (01) acima chegou até mim por um grupo de Whatsapp. Sendo assim, não há como rastrear a fonte (que pode ou não ter sido o meu contato que enviou). A discussão que tento fazer aqui, contudo, é a seguinte: um jornal, impresso ou virtual, não publicaria uma "notícia” neste formato. O único trecho de (01) que emula o gênero notícia (e, acredito, emula uma notícia oral) é “o COVID-19 é imune a organismos com um PH maior que 5,5. VIROLOGY Center, Moscou, Rússia”. É um trecho bastante semelhante às chamadas orais que ouvimos em noticiários em áudio ou em vídeo, mas nunca por escrito. Porém, como estamos falando de Whatsapp, que, ao mesmo tempo, suporta textos em áudio e escritos, vídeos, links, imagens e diversos outros recursos, coage os textos que circulam por ali a terem determinado formato: não são comuns textos muitos longos; as frases também tendem a ser curtas, normalmente cortadas em mensagens diferentes; o uso de recursos visuais (os emojis) são frequentes... enfim, vários são os aspectos que forçam o texto escrito suportado pelo Whatsapp a ser diferente dos presentes em outros suportes. É apenas na interrelação entre gênero e suporte que um texto como (01) pode ser lido como uma "notícia” (notemos, inclusive, a expressão que abre o texto: “Boas notícias”).

Além de circular por redes sociais, podemos também encontrar fake news em sites devotados à publicação de notícias. Ou seja, em um suporte convencional. Contudo, como já discutimos anteriormente, ao se perceber que o suporte traz apenas notícias mentirosas, o leitor passa a enquadrá-lo como suporte de outro gênero: a paródia. Sendo assim, para que um portal de notícias possa suportar fake news, ele precisa, também, suportar notícias (e anúncios, e colunas e diversos outros gêneros e elementos presentes em um portal de notícias), conseguindo emular um portal com credibilidade.

O que temos visto, com muita frequência, são portais tendenciosos e bastante enviesados ideologicamente (o que compromete, pela avaliação social dos leitores, a aceitabilidade destes textos por pessoas que não compartilhem daquele viés ideológico, mas que engaja os que compartilham) suportando "notícias" que são pontos de vista sobre determinados fatos, mas que, de forma alguma, são textos presentes apenas nestes portais. Não cabe aqui nos aprofundarmos na discussão, mas os estudos do texto entendem que não há gêneros “puros”, mas que as várias práticas textuais e discursivas se mesclam e dão origem a novos gêneros a cada troca enunciativa. Sendo assim, não é uma característica apenas de editorias consideradas "tendenciosas” 
que os jornalistas deem suas interpretações dos fatos, o que nos leva, novamente, a perceber como não é simples traçar uma linha que separe o que é "notícia” do que é "fake news" na contemporaneidade.

Retomando o ponto anterior, então, o que temos são portais que criam um ambiente em que o leitor se sente seguro de que está lendo informação de qualidade, o que torna a aceitabilidade do texto maior, que veiculam, ao mesmo tempo, notícias e fake news. Um exemplo é o site Terça Livre, que, inclusive, está sendo investigado pela Polícia Federal no presente momento. Nas imagens abaixo, é possível contrastar as características imagéticas e textuais comuns ao portal supracitado e um portal de notícias confiável.

Figura 1: Home do portal Terça Livre.

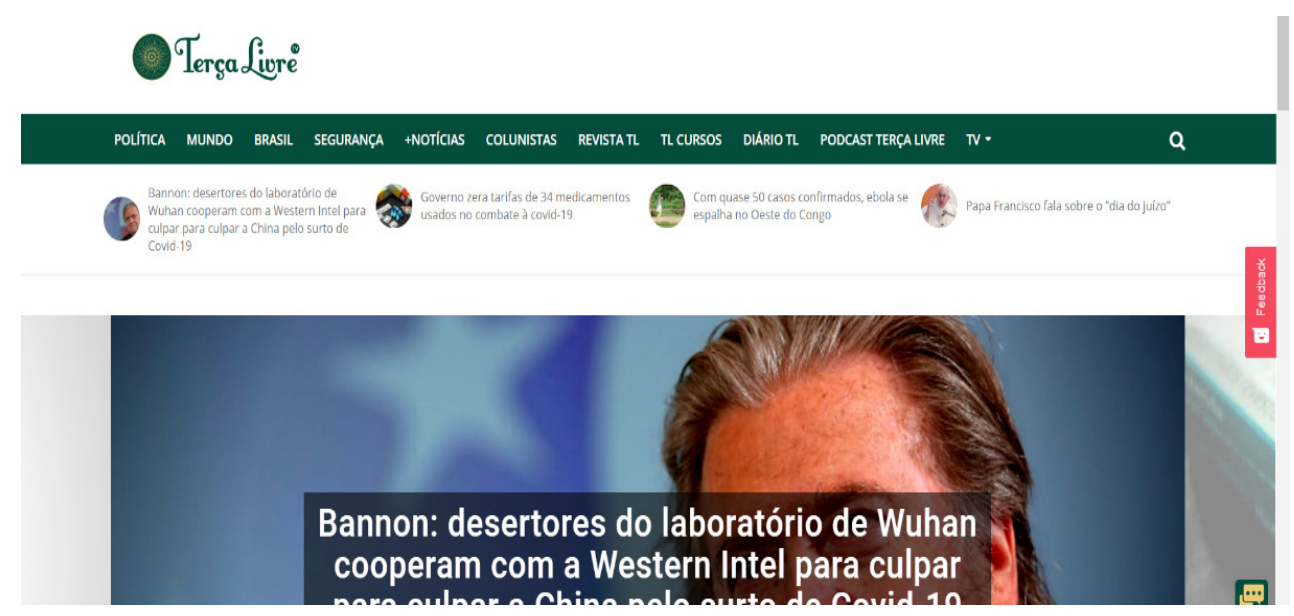

Fonte: https://www.tercalivre.com.br/. Acesso em: 14 jul. 2020.

Figura 2: Home do portal Folha de São Paulo

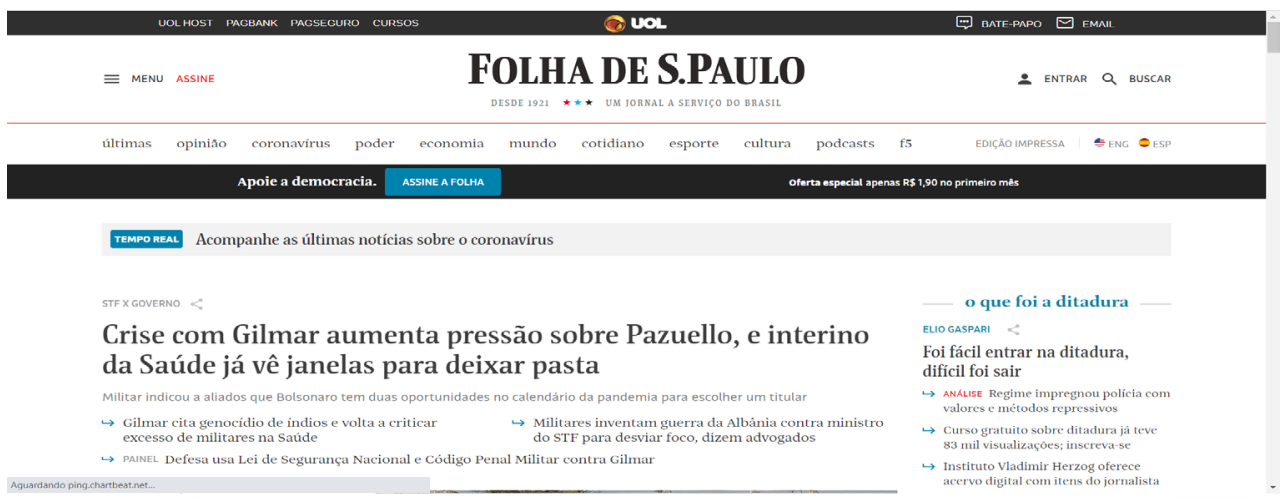

Fonte: https://www.folha.uol.com.br/. Acesso em: 14 jul. 2020.

Comparando as imagens acima, é possível notar a disposição dos elementos do site (ainda que na figura 2 não apareça nenhuma foto por conta da edição de imagens): o nome do portal acima e em destaque; as editorias posicionadas em uma linha logo abaixo do nome; 
notícia principal em destaque (fonte maior); links para notícias dispostas ao redor da principal (em fonte menor) etc. Diversas são as características em comum entre os dois, o que os torna, visualmente, muito semelhantes. Neste sentido, a aceitabilidade passa pelo suporte e, inclusive, pelo aspecto visual deste.

\section{INTERAÇÃO ENTRE SUJEITOS E TEXTUALIDADE}

A respeito da construção de sentidos, Bakhtin coloca que ambos, falante e ouvinte, escritor e leitor, trabalham juntos:

O ouvinte, ao perceber e compreender o significado (linguístico) dos discursos, ocupa simultaneamente em relação a ele uma ativa posição responsiva: concorda ou discorda dele (total ou parcialmente), completa-o, aplica-o, prepara-se para usá-lo, etc; essa posição responsiva do ouvinte se forma ao longo de todo o processo de audição e compreensão desde o seu início, às vezes, literalmente, a partir da primeira palavra do falante. Toda compreensão da fala viva, do enunciado vivo é de natureza ativa e responsiva (embora o grau desse ativismo seja bastante diverso); toda compreensão é preenchida de resposta, e nessa ou naquela forma que a gera, obrigatoriamente: o ouvinte se torna falante (BAKHTIN, 2003, p. 271).

Evidentemente, o que Bakhtin discorre a respeito da fala pode ser entendido a respeito de textos de natureza escrita da mesma forma. Ainda que a resposta não aconteça simultaneamente, ela é dada no momento em que o leitor se encontra com o texto. Neste sentido, o que cabe salientar é que o leitor do texto é também produtor daquele sentido: ele não recebe passivamente, mas interpreta, posiciona-se, responde.

Contudo, há uma sutileza aqui que cabe destacar: pela própria natureza das redes sociais, não se passa adiante uma notícia recebida de forma que esta resposta ao texto fique explícita. Dito de outra forma: em uma situação em que alguém lê e reconta, existe a exteriorização da subjetividade daquele interlocutor que agora é (co)locutor, e esse texto "recontado" traz marcas explícitas da resposta, do posicionamento, da compreensão daquele que repassa. Quando se “compartilha”, “retweeta” ou “encaminha” um texto recebido, a única leitura explícita que se pode fazer a respeito do posicionamento desse leitor-compartilhador é a de que ele julga aquela informação relevante (ainda que relevante para ser desmentida, ou relevante para ser criticada).

Porém, a partir da leitura de Bakhtin, podemos entender que o simples ato de retransmitir a mensagem já é marca da subjetividade daquele interlocutor. Ele "concorda ou discorda dele (total ou parcialmente), completa-o, aplica-o, prepara-se para usá-lo” (BAKHTIN, 2008, p. 271). A mensagem passada adiante é a de que o leitor-compartilhador reagiu àquele texto e, portanto, passa a ser autor, produtor de sentido também. E é justamente aqui que a ideia da credibilidade do suporte se encontra com a responsabilidade ética: repassando uma fake news, o leitor-compartilhador empresta aspectos da sua identidade, sua credibilidade, sua leitura de mundo, seus anseios e desejos para aquele texto que leu (se leu) e compartilha. Portanto, a fake news ressignifica a partir de cada novo compartilhamento. Sua informatividade é afetada a cada novo compartilhamento. 


\section{UMA PROPOSTA DE ANÁLISE}

Para que o que viemos discutindo até aqui não se esgote em elucubrações filosóficas, gostaria de propor uma análise textual, com base nos fatores de textualidade (KOCH, 2009) e nas discussões sobre suporte feitas anteriormente. Esta análise, evidentemente, não pretende esgotar as possibilidades, mas serve para colocar em evidência os aspectos linguísticos e extralinguísticos mobilizados em uma fake news.

O texto em questão (em anexo) foi veiculado pelo Facebook e acessado e salvo em fevereiro de 2019. Atualmente, já foi removido. Apesar de estar "assinado", não foi compartilhado a partir da página "Observatório de Direita Brasileiro". O texto não tinha links: foi copiado e colado nas postagens das pessoas que o compartilharam, o que torna a sua autoria impossível de ser mapeada. Dito de outra forma, sua origem se perdeu, e o produtor do texto pode ser virtualmente qualquer pessoa. Estando a autoria perdida, contudo, ainda pode-se tecer elucubrações a respeito da intencionalidade do texto: $\mathrm{o}$ autor pretende que se tornem autores todos os que compartilharam o texto em suas próprias páginas, sem links, justamente para que a sua autoria não seja rastreada. O efeito de sentido, contudo, é o de que todas as pessoas são autoras do texto também: o endossam, acreditam nele, atribuem a ele alta informatividade.

No outro lado da mesma moeda, a aceitabilidade deste texto está parcialmente garantida quando ele chega ao leitor que já compartilha práticas sociais com aquele emissor. O leitor ideal de um texto como esse é alguém capaz de acreditar nas informações ali expostas, o que pode ser conseguido pelo vínculo social que o locutor e o interlocutor compartilham: seja amizade, seja prestígio, seja posição social, seja a crença de que aquele emissor é fidedigno, enfim: muitas podem ser as razões que tornam a aceitabilidade daquele texto maior. Por outro lado, como aspecto pragmático, é possível que isso seja o contrário: vindo de um locutor de quem se desconfia, qualquer texto passa a perder aceitabilidade. A imagem do emissor está constantemente sendo monitorada justamente em função da aceitabilidade de seus textos pelos leitores.

A situação na qual o texto é produzido é um ponto bastante sensível, uma vez que ela precisa ser bastante precisa: fora de um contexto social e pragmático relevante, a fake news não sobrevive. No texto que estamos analisando, por exemplo, o contexto era o rompimento da barragem de Brumadinho, em 25 de janeiro de 2019. Era o início do mandato do atual presidente, que já chegou ao poder com um alto índice de rejeição para o começo de um mandato (51\%, de acordo com IBOPE, 2019), e um contexto, possibilitado pelas eleições, em que países latino americanos passaram a ser vistos como inimigos do atual governo porque seriam, supostamente, aliados ao governo petista. Estas informações são importantes porque possibilitam entender o papel das menções a "cubano" e "venezuelano" (com supostos mandados de prisão na Colômbia) como responsáveis por um atentado que teria causado o rompimento da barragem de Brumadinho com a intenção de dificultar a atuação do presidente.

Portanto, há uma ligação bem evidente entre o contexto no qual o texto foi produzido e a informação que ele pretende passar: seriam informações relevantes para quem, dentro do contexto mencionado, estava se perguntando sobre as causas do rompimento da barragem. Depois de decorrido determinado tempo, a informatividade do texto é nula. Isso não é completamente diferente do que ocorre com notícias verdadeiras, que, em maior ou menor grau, também estão sujeitas a perderem relevância na medida que não informem mais. 
Porém, ainda sobre a informatividade, voltamos a um ponto que já abordamos neste trabalho: é necessário que o autor do texto saiba que está veiculando uma informação mentirosa e com a intenção de enganar. Assim, a informação veiculada pelo texto é nula em contraste com a realidade, mas a situação discursiva permite que ela possa ser interpretada como verdadeira. Dito de outra forma, a informatividade das fake news vai ser maior quanto maior for a aceitabilidade destes textos em uma inserção discursiva favorável. É necessário que haja uma construção discursiva compartilhada entre os leitores ideais que permita o surgimento de narrativas falsas. Essa formação discursiva vai, além de incentivar o surgimento destas narrativas, incorporá-las como pano de fundo para o surgimento de novas. A situacionalidade, portanto, precisa ser criada de forma discursiva.

Isto que dissemos está completamente de acordo com a visão de Koch (2009), para quem é necessário que exista conhecimento compartilhado entre autor e receptor do texto.

Não só os conhecimentos prévios são de extrema importância no processamento textual e, portanto, para o estabelecimento da coerência, como também os conhecimentos partilhados - ou pressupostos como partilhados - entre os interlocutores, que vão determinar, por exemplo, o balanceamento entre o que precisa ser explicitado e o que pode ficar implícito no texto (KOCH, 2009, p. 45).

A coerência pretendida pelo texto, portanto, está necessariamente atrelada aos fatores analisados anteriormente. Não se pode pensar na coerência das fake news em termos estritamente linguísticos (como não se poderia em nenhum outro texto, é verdade) porque sua intenção, sua recepção e aceitação e, até mesmo, o seu grau de informação dependem do compartilhamento de conhecimentos (falsos, se comparados à realidade) daqueles sujeitos envolvidos na interação. Para uma notícia convencional, o conhecimento compartilhado entre locutor e interlocutor não precisa ser tão grande, pois a notícia se propõe justamente a informar e, assim, aumentar o conhecimento compartilhado entre eles.

Nas fake news, no entanto, o que parece haver é o compartilhamento de enunciados que vai servir à desinformação, justamente por ela não trazer conteúdos verdadeiros. Para os interlocutores que compartilham estas crenças sobre o mundo, o texto é informativo e coerente. Para os que não compartilham, o texto é completamente incoerente. Para os interlocutores que se dispõem a ler e interpretar o texto, buscando elementos que possam atribuir coerência a ele, o efeito é ainda maior: na busca de uma coerência que não virá, o interlocutor passa a questionar o locutor, o gênero, a realidade circundante e, por extensão, os gêneros textuais de repasse de informação.

\section{CONSIDERAÇÕES FINAIS}

O percurso que tentamos fazer neste artigo foi o de mapear alguns pontos relevantes para a discussão das fake news como um gênero textual, passando pela análise dos fatores linguísticos e extralinguísticos que concernem a este tipo de texto. Procuramos fazer um paralelo com o gênero "notícia”, apesar de entendermos que não se trata da mesma coisa ou de um subgênero, mas pelos pontos de intersecção possíveis entre as circulações e as práticas sociais. 
Entendemos que este é um assunto novo, muito amplo e não esperamos, com isso, esgotar ou encerrar a discussão, mas, pelo contrário, começar a pensar em um horizonte para discutirmos estes textos, sua inserção social e sua repercussão nas práticas cotidianas. Se não for possível identificarmos estes textos apenas por seus aspectos formais, que sejamos leitores críticos e que nosso letramento para o uso de redes sociais passe, também, pelo questionamento dos fatores que apontamos neste artigo.

\section{REFERÊNCIAS}

BAZERMAN, Charles. Gêneros textuais, tipificação e interação. São Paulo: Cortez, 2005.

BAKHTIN, Mikhail. Estética da criação verbal. 4. ed. São Paulo: Livraria Martins Fontes, 2003.

BIONDO, Delson. A semântica da palavra mentira e o seu protótipo cognitivo: novas evidências empíricas. 1994. 99 f. Dissertação (Mestrado) - Curso de Pós-graduação em Letras, Setor de Ciências Humanas, Letras e Artes, Universidade Federal do Paraná, Curitiba, 1994. Disponível em: https://hdl.handle.net/1884/24375. Acesso em: 10 jul. 2020.

DELMAZO, Caroline; VALENTE, Jonas C. L. Fake news nas redes sociais online: propagação e reações à desinformação em busca de cliques. Media \& Jornalismo, Lisboa, v. 18, n. 32, p. 155-169, abr. 2018. Disponível em http://www.scielo.mec.pt/scielo.php?script=sci_ arttext\&pid=S2183-54622018000100012\&lng=pt\&nrm=iso. Acesso em: 12 jul. 2020. KOCH, Ingedore Grunfeld Villaça. Introdução à Linguística Textual. 2. ed. São Paulo: Martins Fontes, 2009.

KOCH, Ingedore Grunfeld Villaça; TRAVAGLIA, Luiz Carlos. A coerência textual. 3. ed. São Paulo: Contexto, 1991.

MARCUSCHI, Luiz Antonio. Produção textual, Análise de Gêneros e Compreensão. São Paulo: Parábola, 2008.

SILVA, Pollyanna Honorata. Os gêneros jornalísticos e as várias faces da notícia. 2007. 141 f. Dissertação (Mestrado) - Curso de Letras, Universidade Federal de Uberlândia, Uberlândia, 2007. Disponível em: https://repositorio.ufu.br/handle/123456789/15506. Acesso em: 10 jul. 2020. 


\section{ANEXO}

Uma fonte ligada a ABIN confirmaram nessa tarde que a Polícia Rodoviária Federal deteve nessa tarde, próxima a cidade de Itaguará, cerca de 68 km de Brumadinho, um venezuelano e um cubano.

O carro em que viajam estava em alta velocidade, houve troca de tiros eum terceiro homem foi morto durante a perseguição.

Uma funcionária que sobreviveu a tragédia, confirmou ter ouvido umaexplosão antes do rompimento da barragem. A fonte informou ainda que oVenezuelano é Juan Pablo Mercês, ex guerrilheiro das FARCS, possui 7 mandatos de prisão na Colômbia. O cubano é Antonio Cabalero, conhecido instrutor da Polícia Secreta do Governo Castro, condecorado com a Estrela Vermelha, por sua atuação destacada em ações de sabotagem na guerra civil de Angola

Até agora o interrogatório apurou que várias células terroristas venezuelanas se infiltraram no território nacional, desde a vitória deBolsonaro no primeiro turno das eleições, em outubro.

O objetivo das células são promover atentados terroristas visando sabotar as principais atividades econômicas que compõe as exportações brasileiras, aprofundando a crise econômica e , ao mesmo tempo, frustrando a abertura econômica conduzida por Paulo Guedes.

As células tem como alvo estradas, linhas férreas e portos da infraestruturade exportação de soja e carne bovina. Barragens e estradas de ferro da Vale e plataformas e oleodutos da Petrobrás.

As ações vinham sendo planejadas para início de março, com objetivo defrustrar as votações da reforma da previdência no Congresso, outro item fundamental para recuperação econômica.

No entanto, o reconhecimento do governo brasileiro de Juan Guaidó como presidente da Venezuela, anteontem, as ações foram antecipadas.

A ABIN , Polícia Federal e Polícia Rodoviária Federal, prosseguem as buscas por mais 5 células terroristas infiltratadas.

Fonte: ODB- Observatório Direita Brasileira

Recebido em: jul. 2020.

Aceito em: nov. 2020. 